\title{
Depression and Suicidal Ideation among Older Adults of Kashmir
}

\author{
Shabnum Ara $^{1 *}$, Rakshanda Ahad ${ }^{1}$
}

\section{ABSTRACT}

The present study was undertaken to map the ground trends of depression and suicidal ideation among elderly Kashmiris in association with connected socio-demographic variables and also to find the relationship of depression with suicidal ideation. The sample consisted of 184 older adults (102 elderly males \& 82 elderly females) taken from different districts of Kashmir. The age of the sample group ranged from 58-76 years with mean age of 67 years. Purposive sampling technique was used for research purpose. Aaron Beck's Depression Inventory (BDI-II 1996) and Beck \& Steer's Suicide Ideation scale (BSSI 1991) was used. T-test was used to test the significance of difference in depression and suicidal ideation between various groups and Pearson's Product Moment Correlation was used to determine the relationship between depression and suicidal ideation. The findings of the present study revealed that there is no significant mean difference in the depression level of older adults with respect to various sociodemographic variables. Further, the findings of the present study reveal that there is significant mean difference in the suicidal ideation of educated and uneducated elderly as is true for rural and urban older adults. However, no significant mean difference was found in suicidal ideation of male \& female older adults and also no significant mean difference was found in the suicidal ideation of those elderly whose spouse are alive and those who are widowed. Results further reveal that depression has significant positive correlation with suicidal ideation indicating that depression acts as risk factor for suicidal ideation.

Keywords: Depression, Suicidal Ideation, Elderly, Kashmir.

Ageing is a universal process associated with certain changes that take place in an organism leading to morbidities, disabilities and even death. The beginning of old age is 60 or 65 years which is roughly equal to retirement ages in many developed and developing countries (Gorman M. et al 1999). However, "there is no single age at which we can say that people cross the threshold into old age. As health care facilities improve in countries, the proportion of the elderly in the population and the life expectancy after birth increase accordingly. This is the trend which has been seen in both developed and developing countries. The rise in the proportion of the ageing population represents one of the most significant demographic shifts in history. In 1950

\footnotetext{
${ }^{1}$ Research Scholar, University of Kashmir, Srinagar, India

*Responding Author

(C) 2016 I S Ara, R Ahad; licensee IJIP. This is an Open Access Research distributed under the terms of the Creative Commons Attribution License (http://creativecommons.org/licenses/by/2.0), which permits unrestricted use, distribution, and reproduction in any Medium, provided the original work is properly cited.
} 


\section{Depression and Suicidal Ideation among Older Adults of Kashmir}

there were 205 million people who were over 60, in 2000 there were 606 million people and by 2050 there will be 2 billion elderly people. Again two-thirds of the world's elderly people live in developing countries. It has been documented that elderly are more prone to psychological problems and depression is the commonest geriatric psychiatric disorders. Depressive symptoms and depressive disorders are a substantial mental health problem for older adults (Blazer et al., 1987; Zarit and Zarit, 1998). In fact the elderly in India face a multitude of social and psychological problems. In 1966, the Mental Health Advisory Committee to Govt. of India suggested a prevalence rate of mental illnesses of 20 per 1000 population with 14 per 1000 in rural areas (Elnagger $\mathrm{MN}$ et al). As age advances there is increased morbidity and functional loss, also presence of a variety of depressive factors and occurrence of varying life events greatly impact on one's psychological status, making them more prone to depression. Symptoms in older persons may differ somewhat from symptoms in other populations. Depression in older people is often characterized by memory problems, confusion, social withdrawal, loss of appetite, inability to sleep, irritability and in some cases delusions and hallucinations. It's natural to feel grief in the face of major life changes like those so many older people experience, such as retirement, leaving a home of many years or losing a loved one. Although there is no single, definitive answer to the question of cause, many factors - psychological, biological, environmental and genetic - likely contribute to the development of depression. The radical change in the social structure over past few decades has eroded the family's ability to care for elderly as well as decrease co-residence of adult children with the elderly. Many studies have indicated severe under-recognition and undertreatment of depression in the elderly, even in developed counties ( Maletta G, et al 2000; Nierenberg AA, et al 2001). Depression is expensive financially and in terms of human life. People with depression have a substantially increased risk for suicidal ideation and eventually in several cases early death. Even when depression in older people seems to have less symptoms, the risk for becoming suicidal in over 75 years old people is $30.5 \%$ (in comparison to 3.4\% in people below 25 years of age (Weyerer and Bickel 2007).

\section{Suicidal ideation}

Suicidal ideation is the existence of thoughts pertaining to ending one's own life. It may vary in seriousness depending on the specificity of suicide plans and the degree of suicidal intent (American Psychiatric Association, 2003). Suicide ideation, which comprises suicidal thoughts or threats devoid of action, is more common than suicide attempts and completed suicides and its prevalence varies widely. Lifetime prevalence of suicidal ideation has been reported to range from $2 \%$ to $18 \%$ (Kessler et al., 1999; Weissman et al., 1999). Suicidal ideation can vary significantly in different age groups. Suicidal ideation among the elderly has been suggested to be around 4\% (Skoog et al., 1996). Suicidal ideation can be of a habitual or chronic as well as of an acute nature (Goldney et al., 1989; Diekstra \& Garnefski, 1995). Suicidal ideation can be manifested from transient thoughts with respect to the worthlessness of life and death wish, to permanent, concrete plans for killing oneself and obsessive preoccupation with self-destruction. Suicidal ideation may be an aspect of depressed mood and also from the other point of view, a coping strategy with such a mood. Freud proposed in the influential 1917 paper, Mourning and 
Melancholia that most individuals cope with the loss of a loved person through the experience of mourning. However, he believed that there are other vulnerable individuals for whom the loss experience is unbearable and generates enormous anger. The individual feels ambivalence but preserves the mental image of the loved one by internalization and it becomes part of the ego. Feelings of anger towards the lost objective are not possible to express and so they are transformed into self-sensure and the wish to harm oneself. When these feelings reach a critical pitch, they lead to the urge to destroy the self.

Early cognitive accounts of suicidal behaviour were developed from cognitive theories of depression (Beck et al., 1975). Suicidal patients were assumed to share the frequent occurrence of depressed patient's negative thinking, compounded by logical errors, and a tendency for longterm belief structures to be activated by current depression. Beck with his colleagues (1975; 1990) showed in their research that there is a strong relationship between life stress and suicidal behaviour. When depressed patients believe that there is no solution to their problems, they consider suicide as a way out of an intolerable and hopeless situation.

Teasdale et al. (1988) proposed a differential activation theory (DAT), which suggests that during episodes of depression, associations are formed between sad mood and a constellation of negative processing bias. With each occurring episode of depression, the network of depressive cognitions is strengthened, elaborated and becomes increasingly accessible. Joiner et al. (2003) and Lau et al. (2004) suggested that this theory could be extended to the explanation of recurrence of suicidal behaviour. Painful and fear-inducing qualities of suicidal behaviour can diminish with repetition, while opposing processes may intensify. Williams et al. (2005a; 2005b; 2006) refined this theory further in their reports. DAT suggests that the risk of future suicidality is dependent on the extent to which suicidal thoughts and plans have become a part of the processing pattern that is reactivated when low mood reoccurs.

\section{Present study:}

To age is to grow and decline at same time; the numerous losses which elderly confront as they approach their twilight years has serious impact on their mental health. The review of literature has shown that in India and particularly in Kashmir, the mental health issue of elderly is a neglected area and little is known about their subjective conditions. The need to generate a knowledge base appropriate and relevant for addressing the psychological impact of old age is imperative and critical. Since, depression and suicidal ideation are interrelated variables and provides significant information about the mental health of the elderly. Therefore, it is expected that this study will add to the existing literature and will also validate facts in this area of knowledge. Furthermore, the study will provide unique information regarding the mental health issues of elderly in this region. Keeping these facts in view the investigators felt the need for carrying out the study of depression and suicidal ideation among older adults of Kashmir. Hence, the study entitled "DEPRESSION AND SUICIDAL IDEATION AMONG OLDER ADULTS OF KASHMIR" is formulated with following objectives: 


\section{Depression and Suicidal Ideation among Older Adults of Kashmir}

1. To assess depression and suicidal ideation among older adults of Kashmir.

2. To compare level of depression and suicidal ideation of older adults of Kashmir with respect to various demographic variables as gender, education, domicile and marital status.

3. To examine relationship between suicidal ideation and depression.

\section{Hypothesis:}

On the basis of above objectives, the following hypotheses have been formulated:

Ho1: There is no significant difference in the depression level of male and female older adults of Kashmir.

Ho2: There is no significant difference in the suicidal ideation of male and female older adults of Kashmir.

Ho3: There is no significant difference in the depression level of educated and uneducated older adults of Kashmir.

Ho4: There is no significant difference in the suicidal ideation of educated and uneducated older adults of Kashmir.

Ho5: There is no significant difference in the depression level of rural and urban older adults of Kashmir.

Ho6: There is no significant difference in the suicidal ideation of rural and urban older adults of Kashmir.

Ho7: There is no significant difference in the depression level of married and unmarried (widowed, separated/divorced) older adults of Kashmir.

Ho8: There is no significant difference in the suicidal ideation of married and unmarried (widowed, separated/divorced) older adults of Kashmir.

Ho9: There is no significant correlation between depression and suicidal ideation.

\section{METHOD:}

\section{Participants:}

A sample of 184 older adults (102 elderly males \& 82 elderly females) was taken from different districts of Kashmir and the sample was purely purposive in nature. The age of the sample group ranged from 58-76 years with mean age of 67 years.

\section{Measures:}

Aaron Beck’s Depression Inventory (1996): The Beck Depression Inventory (BDI-II) is a 21item self-report and most widely used instrument intended to assess the existence and severity of symptoms of depression. The BDI-II has been found to have good internal consistency reliability with Cronbach’s alpha ranging from .76 to .95 in psychiatric samples and from .73 to .92 in nonpsychiatric samples. The test-retest reliability of the BDI is also moderate-strong correlations ranging from .48 to .86 with psychiatric patients and from .60 to .83 with non-psychiatric groups. Beck \& Steer's Suicide Ideation scale (BSSI 1991) was used. The BSI is a 21-item self report inventory. First 19 items are scored, whereas the last 2 items, which inquire about the history of 
suicide attempts, are not scored. Each item is rated on scale ranging 0-2. Total scores on the BSI can thus range from 0 to 38 points, with high scores indicating high suicidal ideation and low score indicating low suicidal ideation.

\section{Socio-demographic variables}

These included gender, age categorized into 58 years and above; Muslim religious orientation. Marital status was represented as currently married and currently not married (single, divorced, separated, or widowed). Education was measured as literate versus illiterate. Domicile was represented as belonging to rural and urban.

\section{Procedure:}

The subjects were approached personally and instructed to give their responses on a questionnaire booklet. Assurance of confidentiality was given to the respondents to boost their motivation and reduce bias. After motivating the respondents the questionnaire booklet was provided to each respondent and necessary help was provided by the researchers to assist participants with limited reading and writing ability.

\section{Statistical Analysis:}

The analysis of data was carried out by using appropriate statistical tools. Quartiles $\left(\mathrm{Q}_{1}\right.$ \& $\left.\mathrm{Q}_{3}\right)$ were used to assess the level of depression and suicidal ideation of older adults. In order to find the mean differences between various groups t-test was used. Pearson's product Moment Correlation was used to determine the relationship between depression and suicidal ideation of the elderly Kashmiris.

\section{RESULTS:}

Table1: Frequency distribution of depression and suicidal ideation level among older adults.

\begin{tabular}{|l|l|l|}
\hline Depression & Frequency & Percentage \\
\hline Level & 42 & $22.83 \%$ \\
\hline Mild & 43 & $23.37 \%$ \\
\hline Hoderate & 99 & $53.80 \%$ \\
\hline \hline Suicidal Ideation & 65 & $35.33 \%$ \\
\hline Mild & 112 & $60.87 \%$ \\
\hline Moderate & 7 & $3.80 \%$ \\
\hline High & & \\
\hline
\end{tabular}

The perusal of data fromTable-1 reveals that 22.83\% of older adults have mild level of depression, $23.37 \%$ have moderate level of depression and $53.80 \%$ have high level of depression. It also reveals that $35.33 \%$ of older adults have mild level of suicidal ideation, $60.87 \%$ have moderate level of suicidal ideation and 3.80\% have high level of suicidal ideation. 
Table 2: Comparison of mean scores of Depression and Suicidal Ideation with respect to various socio demographic variables.

\begin{tabular}{|c|c|c|c|c|c|c|}
\hline Variable & Group & $\mathbf{N}$ & Mean & $\begin{array}{l}\text { Std } \\
\text { Deviation }\end{array}$ & df & t-value \\
\hline \multirow{8}{*}{ Depression } & Male & 102 & 28.3529 & 11.32827 & \multirow[b]{2}{*}{182} & \multirow[b]{2}{*}{$-0.063^{\mathrm{NS}}$} \\
\hline & Female & 82 & 28.4634 & 12.26175 & & \\
\hline & Educated & 111 & 27.0721 & 11.63124 & \multirow[b]{2}{*}{182} & \multirow[b]{2}{*}{$-1.912^{\mathrm{NS}}$} \\
\hline & Uneducated & 73 & 30.4247 & 11.64512 & & \\
\hline & Rural & 88 & 29.9062 & 11.80729 & \multirow[b]{2}{*}{182} & \multirow[b]{2}{*}{$1.830^{\mathrm{NS}}$} \\
\hline & Urban & 96 & 26.7614 & 11.46809 & & \\
\hline & Married & 104 & 27.1538 & 12.04181 & \multirow[b]{2}{*}{182} & \multirow[b]{2}{*}{$-1.655^{\mathrm{NS}}$} \\
\hline & Unmarried & 80 & 30.0250 & 11.15594 & & \\
\hline \multirow{8}{*}{$\begin{array}{l}\text { Suicidal } \\
\text { Ideation }\end{array}$} & Male & 102 & 13.4314 & 8.64997 & \multirow[b]{2}{*}{182} & \multirow[t]{2}{*}{$-.540^{\mathrm{NS}}$} \\
\hline & Female & 82 & 13.4314 & 8.64997 & & \\
\hline & Educated & 111 & 11.8108 & 8.12797 & \multirow[b]{2}{*}{182} & \multirow[t]{2}{*}{$-3.952^{* *}$} \\
\hline & Uneducated & 73 & 16.6575 & 8.15513 & & \\
\hline & Rural & 88 & 17.8125 & 7.57185 & \multirow[b]{2}{*}{182} & \multirow[t]{2}{*}{$7.895^{* *}$} \\
\hline & Urban & 96 & 9.2841 & 7.03350 & & \\
\hline & Married & 104 & 13.0385 & 8.56831 & \multirow[b]{2}{*}{182} & \multirow[b]{2}{*}{$-1.274^{\mathrm{NS}}$} \\
\hline & Unmarried & 80 & 14.6375 & 8.27723 & & \\
\hline
\end{tabular}

NS $=$ Not significant $* p \leq 0.05$ Level of Significance $* * p \leq 0.01$ Level of significance

Table-2 shows an overview of t-values of depression and suicidal ideation with respect to various socio-demographic variables. The perusal of the data from the table reveal that there is no significant difference in the depression level of male and female elderly as their obtained t-value of depression is insignificant even at 0.05 level. Thus the null hypothesis Ho1 (There is no significant difference in the depression level of male and female older adults of Kashmir) stands accepted. Also results show that male and female elderly do not differ significantly in suicidal ideation as the obtained t-values are insignificant even at 0.05 level. Thus, null hypothesis Ho1 (There is no significant difference in the suicidal ideation of male and female older adults of Kashmir) stands accepted.

Table-2 further shows an overview of t-values of religiosity, its facets and depression, with respect to educational status of these elderly. It was revealed that there is no significant difference in the depression level of educated and uneducated older adults as the obtained t-value of depression (-1.912) is insignificant even at 0.05 level. Thus the null hypothesis Ho3 (There is no significant difference in the depression level of educated and uneducated older adults of Kashmir) stands accepted. The results of table-2 also reveal that educated and uneducated older adults significantly differ in suicidal ideation as the obtained t-value of suicidal ideation (-3.952) is significant even at 0.01 level. Thus the null hypothesis Ho4 (There is no significant difference in the suicidal ideation of educated and uneducated older adults of Kashmir) stands rejected. 


\section{Depression and Suicidal Ideation among Older Adults of Kashmir}

Table-2 also shows that that there is no significant difference in the depression level of rural and urban elderly as their obtained t-value of depression is insignificant even at 0.05 level. Thus the null hypothesis Ho5 (There is no significant difference in the depression level of rural and urban older adults of Kashmir) stands accepted. The perusal of data from table-2 further reveal that tvalue $(t=7.895)$ of suicidal ideation scores between rural and urban older adults differ significantly $(\mathrm{p} \leq 0.01)$. Thus, null hypothesis Ho6 (There is no significant difference in the suicidal ideation of rural and urban older adults of Kashmir) stands rejected.

Table-2 further shows an overview of t-values of depression and suicidal ideation with respect to marital status of older adults. It was revealed that there is no significant difference in the depression level of married and unmarried (widowed, divorced/separated) elderly as their obtained t-value of depression is insignificant even at 0.05 level. Thus the null hypothesis Ho7 (There is no significant difference in the depression level of married and unmarried older adults) stands accepted. The results of table-2 further reveal that married and unmarried (widowed, divorced/separated) elderly do not differ significantly in suicidal ideation. Thus, null hypothesis Ho8 (There is no significant difference in the religiosity of married and unmarried older adults) stands accepted. t-value is insignificant even at 0.05 level.

Table3: Correlation between Depression and Suicidal Ideation.

\begin{tabular}{|l|l|}
\hline Depression & \multirow{2}{*}{$\mathrm{r}=0.612^{* *}$} \\
\hline Suicidal Ideation &
\end{tabular}

The perusal of data from Table-3 reveals that there is significant positive correlation between Depression and Suicidal Ideation. Thus the null hypothesis Ho9 (There is no significant correlation between depression and suicidal ideation) stands rejected.

\section{DISCUSSION:}

The present study was undertaken to examine the depression and suicidal ideation levels among older adults of Kashmir. After analyzing and interpreting the data it was found that majority of these older adults (53.80\%) have high level of depression. These research findings concur with the earlier findings of Gottfries \& Karlsson (2005) older age is established as a major predictor for depression with $45.2 \%$ of women and $26.9 \%$ of men afflicted by age 70 . These findings are further substantiated by findings of Djernes JK (2006) the prevalence rates for depression in community samples of elderly in India vary from $6 \%$ to $50 \%$. As on suicidal ideation, large proportion (64.67\%) of these older adults was found to have moderate to high levels of suicidal ideation. These findings are in consonance with the earlier findings by Cattell (2000) suicide rates rise with age. The findings of the present study also reveal that there is no significant difference in the depression levels of male and female older adults. The findings differ from the findings of ArunR, et al and Barua A, et al (2010), who found significant difference in the depression level of male and female elderly. No significant difference in the suicidal ideation 


\section{Depression and Suicidal Ideation among Older Adults of Kashmir}

levels of male and female older adults was found. These findings are in line with earlier research findings which show that the thoughts of suicide appear to be unrelated to gender (Murray, 1973; Sorenson \& Rutter, 1991). Also no significant difference in the depression levels of married and unmarried older adults were found. These findings differ from earlier findings of Xie LQ (2010) who found significant difference in the depression level of married and widowed older adults. No significant difference was found in the suicidal ideation levels of married and unmarried older adults. These findings differ from earlier findings (Zimmerman et al., 1995; Kessler et al., 2005) who reported that suicidal ideation is more prevalent among unmarried. Further, no significant difference was found in the depression level of educated and uneducated older adults. However, the findings of the present study reveal that there is significant difference in the suicidal ideation levels of educated and uneducated older adults. Uneducated elderly were found to be higher on suicidal ideation than uneducated elderly. These findings concur with findings of Kessler et al (2005). It was also revealed in the present study that no significant difference exists in the depression levels of rural and urban older adults. However, rural and urban older adults significantly differ in suicidal ideation. Urban elderly were found to have more suicidal ideation than rural elderly. These findings are in line with those of earlier findings by Khan FA et al (2005). The most important finding from the present study reveal that there is a significant positive correlation (0.612) between depression and suicidal ideation which implies that higher the depression more is the likelihood of person to have suicidal ideation or in other words we can say that depression acts as risk factor for suicidal ideation in old age. These research findings are substantiated by earlier findings which identified depression as most consistent risk factor of suicidal ideation in old age (Conwell et al, 1996; Lawrence et al, 2000; Vijayakumar \& Rajkumar, 1999; Beck et al, 1979; Sorenson \& Rutter, 1991).

\section{CONCLUSION:}

Conclusively, the findings of the present study paint a grim picture of the mental health status of older adults of Kashmir as majority of them were found to have moderate to high level of depression and suicidal ideation suggesting a need for targeted intervention to improve their mental health and prevent suicide. Moreover, the present study indicates that being illiterate and belonging to urban domicile are significant determinants of emotional suffering in these elderly. Last but the most important finding of the present study is that there is significant positive correlation between depression and suicidal ideation which has important implication for clinical practice and future research. As depression places older people at increased risk for suicide the service providers should adopt a more focused perspective on addressing the mental health problems of older and understanding of same shall further influence community mental health programs and policies relevant to them in order to improve psycho-social functioning of these elderly.

\section{LIMITATIONS AND FUTURE DIRECTIONS:}

This study was limited in a number of ways. Since the data were gathered cross-sectionally, the results do not reflect patterns of behavior over time. Also, it is based on self-reported measures 
with no structured psychiatric diagnosis. The sample for study was not too large. Hence, the replication of the study with a larger sample size and a community based sample may make the results generalizable.

\section{REFERENCES:}

American Psychiatric Association (APA). Practice guideline for the assessment and treatment of patients with suicidal behaviors. Am J Psychiatry 2003; 160 (suppl 11): 1-60.

ArunR, KuttyVR, Ravindran S. Prevalence of and correlates of depressive symptoms among inmates of old age home in kottayam, kerela India.

BaruaA, Kar nilamadhab. Screening for depression in elderly Indian population .Indian journal of psychiatry. year 2010;vol 52,issue 2:pg150-153

Beck AT, Kovacs M, Weissman A. Assessment of suicidal intention. The Scale for Suicidal Ideation. J Consult Clin Psychol 1979;47(2):343-352.

Blazer DG, Hughes DC, George LK. 1987. The epidemiology of depression in an elderly community population. Gerontologist 27: 281-287.

Bongaarts J. Household Size and Composition in the Developing World. New York: Population Council, 2001..

Cattell, H. 2000. "Suicide in the elderly.” Advances in Psychiatric Treatment 6: 102-103.

Conwell, Y. (1995) Suicide among elderly persons. Psychiatric Services, 46(6), 563-564.

Department of International Economic and Social Affairs: Periodical on Ageing. Volume1. New York: United Nations, 1985.

Djernes JK. Prevalence and predictors of depression in populations of elderly: a review. Acta Psychiatr Scand 2006; 113(5): 372-387.

Doyle, D.(1992).Have we looked beyond the physical and psychosocial? Journal of pain and Symptom Management, 7,303-311.

Elnaggar MN, Moitra P, Rao MN. Mental Health in an Indian rural community. British J Psych 1974; 46: 327-59.

Fehring, R., Miller, J. and Shaw, C., 1997. Spiritual Well-Being, Religiosity, Hope, Depression, and other Mood States in Elderly People Coping with Cancer. Oncology Nursing Forum, 24(4), pp. 663-71.

Ganatra, H.A., Zafar, S.N., Qidwai, W., \& Rozi, S. (2008). Prevalence and Predictors of Depression among an Elderly Population of Pakistan. Aging and Mental Health, 12, 34956.

Goldney RD, Winefield AH, Tiggeman M, Winefield HR, Smith S. Suicidal ideation in a young adult population. Acta Psychiatr Scand 1989;79(5):481-489.

Gorman M. Development and the rights of older people. In: Randel J, German T, Ewing D (Eds.), The ageing and development report: poverty, independence and the world's older people. London Earthscan Publications Ltd, UK, pp. 3:21; 1999.

Kessler RC, Berglund P, Borges G, Nock M, Wang PS. Trends in suicide ideation, plans, gestures, and attempts in the United States, 1990-1992 to 2001-2003. JAMA 2005;293:2487- 2495.

Kessler RC. The effects of stressful life events on depression. Ann Rev Psychology 1997;48:191-214.

Khan FA, Anand B, Devi MG, Murthy KK. Psychological autopsy of suicide- a cross-sectional study. Indian J Psychiatry. 2005; 47:73-8 
Lawrence, D., Almeida, O.P., Hulse, G.K., Jabelensky, A.V. \& D’arcy J. Holman, C. (2000). Suicide and attempted suicide among older adults in Western Australia. Psychological Medicine, 30, 813-821.

Madianos MG, Madianou-Gefou D, Stefanis CN. Changes in suicidal behavior among nationwide general population samples across Greece. Eur Arch Psychiatry Clin Neurosci 1993;243:171-178.

Maletta G, Mattox KM, Dysken M. Update 2000- Guidelines for prescribing psychoactive drugs. Geriatrics 2000; 55 (3): 65-72, 75-66, 79.

Murray DC. Suicidal and depressive feelings among college students. Psychol Rep 1973;33(1):175-181.

Nierenberg AA. Current perspectives on the diagnosis and treatment of major depressive disorder. Am J Manag Care 2001; 7 (11 Suppl): S3, 53-366.

Rahul Prakesh, SK Choudhary, Uday Shankar Singh. A Study of Morbidity Pattern Among geriatric Population in an Urban Area of Udaipur Rajasthan. Indian Journal of Community Medicine 3004; 29 (1).

Schwab JJ, Warheit GJ, Holzer CE. Suicidal ideation and behavior in a general population. Dis Nerv Syst 1972;33(11):745-8.

Skoog I, Aevarsson O, Beskow J, Larsson L, Palsson S, Waern M, Landahl S, Ostling S. Suicidal feelings in a population sample of non-demented 85-year-olds. Am J Psychiatry 1996;153(8):1015-20.

Sorenson SB, Rutter CM. Transgenerational patterns of suicide attempt. J Consult Clin Psychol 1991;59(6):861-6

Sorenson SB, Rutter CM. Transgenerational patterns of suicide attempt. J Consult Clin Psychol 1991;59(6):861-6; discussion 867-73.

Venkoba Rao A. Psychiatry of old age in India. International Review of Psychiatry 1993; 5:165170.

Vijayakumar, L., \& Rajkumar, S. (1999). Are risk factors for suicide universal? A case control study in India. Acta Psychiatrica Scandinavica, 99, 407-411.

Weissman MM, Bland RC, Canino GJ, Greenwald S, Hwu HG, Joyce PR, Karam EG, Lee CK, Lellouch J, Lepine JP, Newman SC, Rubio-Stipec M, Wells, JE, Wickramaratne PJ, Wittchen HU, Yeh EK. Prevalence of suicide ideation and suicide attempts in nine countries. Psychol Med 1999;29(1):9-17.

Weyerer, S., Bickel, H. 2007. Epidemiologie psychischer Erkrankungen im höheren Lebensalter, Grundriss Gerontologie Band 14. Stuttgart: Kohlhammer.

XieLQ,ZhangJF,Peng T, JiaoNN . Prevalance and related influencing factors on depressive symptoms for empty nest elderly living in the rural area of yongzhou china . Arch Gerontl geriatric 2010;janfeb, 50(1)

Zarit S, Zarit J. 1998. Mental Disorders in Older Adults: Fundamentals of Assessment and Treatment. Guildford Press: New York.

Zimmerman M, Lish JD, Lush DT, Farber NJ, Plescia G, Kuzma MA. Suicidal ideation among urban medical outpatients. J Gen Intern Med 1995;10:573-576. 